\title{
UN ATAIFOR NORTEAFRICANO: UN ENSAYO DE INTERPRETACIÓN ICONOGRÁFICA
}

Por

GUILLERMO ROSSELLÓ BORDOY

Entre los materiales arqueológicos salvados «in extremis" de una desafortunada intervención en el recinto de la Almudayna de la antigua Madina Mavūrqa (1), destacan unos pocos fragmentos de ataifor decorado en verde $y$ manganeso que plantean una serie de problemas en cuanto a su lugar de origen, morfología e iconografía.

El problema ha motivado un especial interés en torno a la complejidad del tema $\gamma$, si bien algunos aspectos han sido tratados con anterioridad (2), quisiera ahora reincidir en la cuestión, básicamente en lo que se refiere a su problemática iconográfica.

Los fragmentos en cuestión son cuatro, dos de ellos presumiblemente pertenecen a una misma pieza, si bien no hay posibilidad de enlace entre ellos (3); los dos restantes corresponden al mismo tipo formal, pero la exigüidad de lo conservado (fragmentos reducidos de borde) no permite considerarlos como parte integrante de la misma pieza (4).

Desde el punto de vista formal se trata de un ataifor, zafa o bandeja circular para servir viandas, de cavidad alta, pare des curvas, robustas, con reborde plano, bien diferenciado y repie anular, grueso, alto y ancho (fig. 1). Tipológicamente corresponde a la variante "la" de mi sistematización (5). La calidad del barro es compacta, de color rosado-amarillento, tipo sandwich, con cobertura vitrificada muy tenue, amarillenta, que permite transparentar el color del soporte y decoración en verde y manganeso. Las características del barro no son fre-

(1) Puede verse la historia de esta intervención en mi estudio wotes en torn al Castell Reial de Madina Mayúrqa». en Quaderns de Ca la Gran Cristiena, 4. Palma, 1984.

(2) ROSSELLÓ BORDOY, G., «Nuevas formas en la cerámica de época islàmicaw, en B. S. A. L., 39, Palma. 1981. páginas $340-341$.

(3) Son dos los fragmentos descritos como mayor y menor en el presente estudia y que definen la variante wlaw de la serie ataifor. Numero 43 de la colección procedente de la Almudayna (Num. Inv. Gral. MM 17.706).

(4) Números 56 y 57 de la colección de la Almudayna (Núm. Inv. Gral. MM 17.707 y 1.7.708).

(5) ROSSELLÓ BORDOY, G., Ensayo de sistematización de la cerámica drabe en Mallorca, Paima de Mallorca, 1978, 351 págs., 12 láms. y 8 desplegables; nuevas formas en la cerámica de época isiámican, en B.S.A.L., 39. Palma, 1983 , pp. 337-360. 
cuentes entre los materiales aparecidos en yacimientos mallorquines, si bien existen unas pocas piezas similares en lo tocante a pastas y a cobertura vitrea que siempre he considerado norteafricanas (6).

Dentro de la serie ataifor el tipo I y su variante la es de lo más antiguo que encontramos en Mallorca. Su cronología bordea el siglo $X$ y puede perdurar perfectamente a lo largo del siglo XI. Responde a una imitación califal de anteriores prototipos chinos y su incidencia en la tipología cerámica de época califal es muy fuerte: el tipo 1 , perfectamente situable en el siglo $X$, no tendrá la pervivencia de su variante "la", que se prolonga hasta el siglo XII, al menos tal como se desprende del estudio de los materiales islámicos hallados en Pisa.

El ejemplar de la Almudayna y los fragmentos que le acompañan presenta unas características uniformes y considero que su adscripción a un alfar magribí no anda desencaminada. Sin embargo, los aspectos formales no son suficientemente probatorios, pues la pervivencia $y$ difusión de un tipo determinado, en alfares diferentes y con una dilatada secuencia cronológica, dificultan su adscripción a un taller y a un momento precisos. El estado de nuestros conocimientos, por otra parte, no permite mayores precisiones. Sin embargo, considero prácticamente seguro, a falta de análisis de pastas, su origen magribí.

Será el tema decorativo, más bien el sistema decorativo, el que nos permita una mayor precisión, pues el sistema y tema decorativo del ataifor de la Almudayna presentan suficientes elementos de comparación que permiten un análisis depurado de la pieza en cuestión.

Los dos fragmentos de la Almudayna que considero forman parte de una misma pieza podrian describirse del modo siguiente:

\section{FRAGMENTO MAYOR}

Abarca aproximadamente un tercio de la pieza y el perfil puede establecerse adecuadamente con este fragmento, pues se extiende desde la cavidad central hasta el borde, sin solución de continuidad y lo conservado del repié permite su reconstrucción gráfica. El sistema decorativo supone un alto grado de perfección técnica a base de pinceladas sueltas trazadas con pericia, con un perfecto dominio de la técnica. Hay un predominio casi absoluto del trazo a base de manganeso: en cambio, los rellenos en verde o simples toques complementarios, al conservarse muy degradados, aparecen como difuminados o desdibujados (fig. 2 ).

El tema presenta un encuadre de ovas que discurre a lo largo del borde, formado por trazos en cuarto de circunferencia, imbricados, con toques complementarios de verde. Una línea continua marca el plano de ruptura entre el borde $y$ la cavidad del ataifor. El motivo que discurre a lo largo de la cavidad resalta sobre el fondo blanco amarillento, pues ocupa la parte central. Lo conservado podría dividirse, de abajo hacia arriba, en tres sectores: base, tema central $\gamma$ encuadre.

La base está formada por un rectángulo, en disposición horizontal,

(6) ROSSELLO BORDOY, G., «Elementos decorativos en la cerámica árabe de los siglos X y Xln, en Actas de las Jornadas de Cultura Arabe e islámica 11978i, Madrid, 1981, pp. 271-276. 
hecho a base de un doble trazo en manganeso relleno de verde. En el interior, un motivo de ovas apuntadas, superpuestas, quedando los espacios libres rellenos a base de trazos paralelos, hechos a base de pinceladas sueltas dibujadas con fuerza.

El encuadre lo forma una doble línea oval rellena de verde, bordeada exteriormente por pequeños trazos a modo de flecos, en manganeso.

En el tema central observamos un elemento central, alargado, con remate oval decorado con dos registros reticulados, arriba y abajo de la figura y registro central en blanco recortado por dos trazos horizontales de manganeso. En la parte inferior, un adosamiento oval con reticulado que combina el verde y manganeso y un tramo en blanco dispuesto en vertical. La parte superior queda delimitada por un vigoroso trazo en curva en manganeso que enlaza el cuerpo central con el encuadre de la figura.

\section{FRAGMENTO MENOR}

Pequeño trozo de borde y pared de la cavidad del ataifor, restos decorativos en el borde (ovas imbricadas) y en la pared unos manchones al manganeso identificables con una cabellera y ojo (fig. 3).

Para el debido estudio del tema procedía una reconstrucción gráfica del mismo partiendo de la hipótesis de una posible simetría, añadiendo el motivo decorativo del fragmento menor que en sintesis podia in terpretarse como parte de una cabeza, enmarcada por una cabellera tupida y un ojo definido por una mancha oval.

Dibujado sobre papel vegetal el tema conservado y hecho el desarrollo simétrico, pude obtener una lectura coherente: figura en majestad, sentada en cuclillas a la turca, sobre el zócalo rectangular, todo ello enmarcado por el encuadre oval, el trazo curvo superior podría interpretarse como la posición de brazos propia de los orantes. El resultado queda resumido en las figuras 4 y 5 . En ellas puede observarse el calco del tema conservado (fig. 4) y el resultado del desarrollo simétrico de lo conservado (fig. 5 ).

Como es normal en todo intento de restitución gráfica, el resultado es discutible y sujeto a controversia y precisamente dada la complejidad del tema considero que esta controversia es no sólo conveniente, sino necesaria.

El conjunto, en principio, puede interpretarse como una figura en majestad, sentada, con los brazos en actitud orante. El rectángulo inferior y el remate oval pueden interpretarse como la esquematización del sitial o trono; los espacios ovales que enmarcan la figura podrían ser parte integrante de este trono o bien las rodillas del personaje en majestad sentado a la morisca.

Paralelos para documentar esta hipótesis no faltan; sin embargo, antes de entrar en los paralelismos iconográficos, sería conveniente entrar primero en la compleja identidad que la técnica decorativa nos ofrece.

El tema de ovas imbricadas que se desarrolla a lo largo de la orla lo tenemos perfectamente definido en el ubacino" 2 (fia. 6) de la serie, magníficamen- 
te publicada por Berti y Tongiorgi (7), fechado a inicios del siglo XI y considerado de factura magribi. El perfil, además, corresponde a un tipo la, similar en casi todos sus aspectos formales al ataifor de la Almudayna. El único elemento distorsionante sería el repié anular: ancho y bajo en el ejemplar pisano; estrecho $y$ alto en el de la Almudayna.

A través del "bacino" pisano observamos también el sistema de decoración reticular, elemento muy característico de la decoración norteafricana, que tiene sus raíces en el mundo beréber preislámico (8) y pervive aún hoy en las cerámicas populares de este ámbito geográfico. La técnica reticulada la observamos también en el "bacino" 58 y en los ataifores tunecinos dados a conocer por Daoulatli (9) - núm. $\uparrow 6$ de procedencia qayrawãní, núm. 17 procedente de Sabra y núm. 9 procedente de Raqqada (fig. 7)- Desgraciadamente, de estos últimos carecemos de perfiles, queja ya inveterada en nuestros estudios cerámicos, si bien los números 9 y 16 de Daoulatli podrían identificarse con una forma 1 y el número 17 , con toda seguridad, corresponde a nuestro tipo II, de perfil quebrado, como el número 58 de Pisa, que corresponde claramente a una variante norteafricana del tipo II (fig. 8).

Interesa destacar que tanto en el ejemplar de la Almudayna como en Pisa 2 y Sabra, el tema decorativo destaca sobre el fondo claro que recubre la cavidad del plato. Para mi es un sintoma de antigüedad directamente enlazable con las técnicas decorativas del siglo $\mathrm{X}$, mientras que el ejemplar Pisa 58 presenta una decoración tupida que enlaza con los sistemas del siglo XI, que tienden a recubrir todo el espacio a decorar sin apenas dejar espacios libres.

Cronológicamente el ejemplar de Raqqāda, aglabí, puede situarse en el siglo $X$ y presenta una evidente berberización decorativa; el ejemplar de Qayrawān, considerado fatimí por Daoulatli, tiene que situarse a caballo entre los siglos $X$ y $X I$, asi como el de Sabra, fatimí o zirí. El bacino Pisa 2 lo consideran como de inicios del siglo XI, así como el Pisa 58.

No veo inconveniente, pues, en situar a inicios del siglo Xl el ejemplar de la Almudayna y enlazarlo estilísticamente con Pisa 2 y Qayrawãn.

En cuanto a la figura en majestad, en actitud orante, podemos encontrar innúmeros paralelos. En primer lugar hay que observar la frontalidad de la figura y, de consiguiente, su hieratismo. Lo tenemos en cerámica, tallado sobre marfil y madera y pintado sobre marfil. El orante cubre todo el espacio geográfico de la dãr al.Isläm desde Susa (10) a Granada (11), con una amplia pervivencia cronológica. Tan sólo unos pocos ejemplos que avuden a centrar el tema: figura central del bote de marfil de la colección Riaño (fig. 9), hoy en el Museo Victoria y Alberto (Ferrandis, 14) (12); figuras laterales del bote del Museo del Louvre, también procedente de la colección Riaño (Ferrandis, 13) (figu-

(7) BERTI, Graziella, y TONGIORGI, Liana, I vacini ceramici medievali delfe Chiese di Pisa, L'Erma di Bretschneider. Roma, 1981.

(8) MOREAU, J. B., "Les grands symboles méditerranéens dans la poterie algériennew, S. N. E. O., Aigeria, 1976. 191 páginas.

(9) DAOULATLI, A., Poteries et céramiques tunisiennes, Institut National d'Archéologie et d'Art, Túnez, 1979, 107 págs. Vêanse las páginas $30-31,42-45$.

(10) ROSEN AYALON, Mirian, La poterie islamique, Paris, 1974, Vease pógina 67, fig. 190, y lámina lli, fig. 240. Este último enlaza directamente con el ejemplar entrevisto por mí en la Alhambra y con la pieza de Sabra indicada en la nota siguiente. 
ra 10); figurita pintada en el bote de la Walters Arts Gallery de Baltimore (Ferrandis, 29) (fig. 11): orantes de Susa (fig. 12), dados a conocer por Rosen Ayalon, y fragmentos de orantes en los depósitos del Museo de la Alhambra.

Sirva esta nota para plantear un nuevo motivo de discusión no sólo en lo que respecta a la problemática iconográfica, sino a las relaciones comerciales Norte de África-Baleares-Italia, donde la cerámica ocupa un importante papel : como documento probatorio de que no siempre las relaciones entre islam y Cristiandad tuvieron como punto de partida la incompresión y la guerra.

(11) Pude contemplar una pieza de este tipo en una de las vitrinas del Museo de la Alhambra en una rápida visita realizada en 1974 . Posteriormente no me ha sido posible localizar este interesante ejemplar, aun después de investigar en los fondos almacenados en dicho museo. Lo publicado por mí en aDe nuevo los animales de juguete y otros aspectos de coroplastia andalusín en Actas del $\mathrm{V}$ Coloquio Hispano-Tunecino, Palma de Mallorca, 1979. Madrid, 1983, pp. 205-212, no responde exactamente al típico orante que observamos también en el estudio de ZBISS, SLIMANE MUSTAFA, eLes sujets animés dans le décor musulman d'Ifriqiyah (Tunisie)*, en Bulletin Archéologique, 54, París, 1957, pp. 297-235. Ver figura 24 descrita como "personnage décapité, privé de ses membres supérieurs et assis à la turquen. Procede de Sabra y está modelado en barro cocido.

(12) FERRANDIS TORRES, J., Marfiles arabes de occidente, Madrid, 1935-1940, 2 vols. 


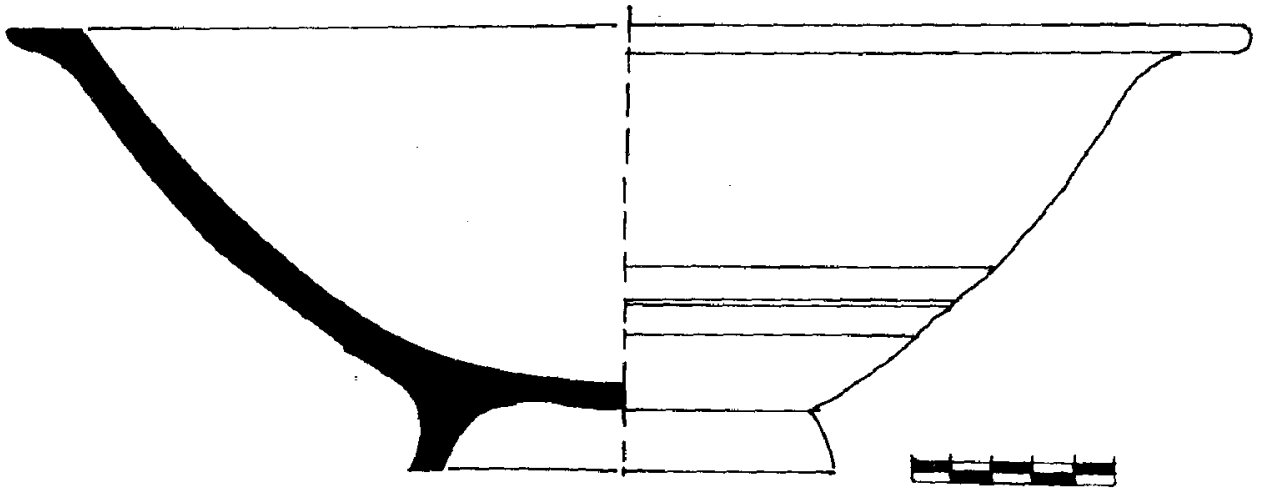

Figura 1.-El ataifor norteafricano de la Almudayna: perfil. 
UN ATAIFOR NORTEAFRICANO... I Rossello

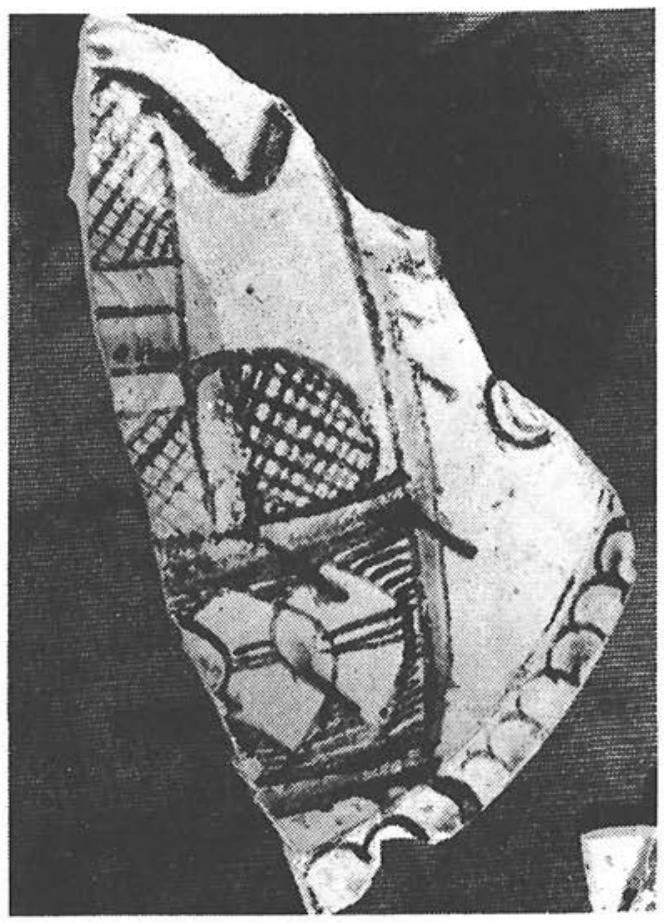

Figura 2.-Fotografia del fragmento mayor.

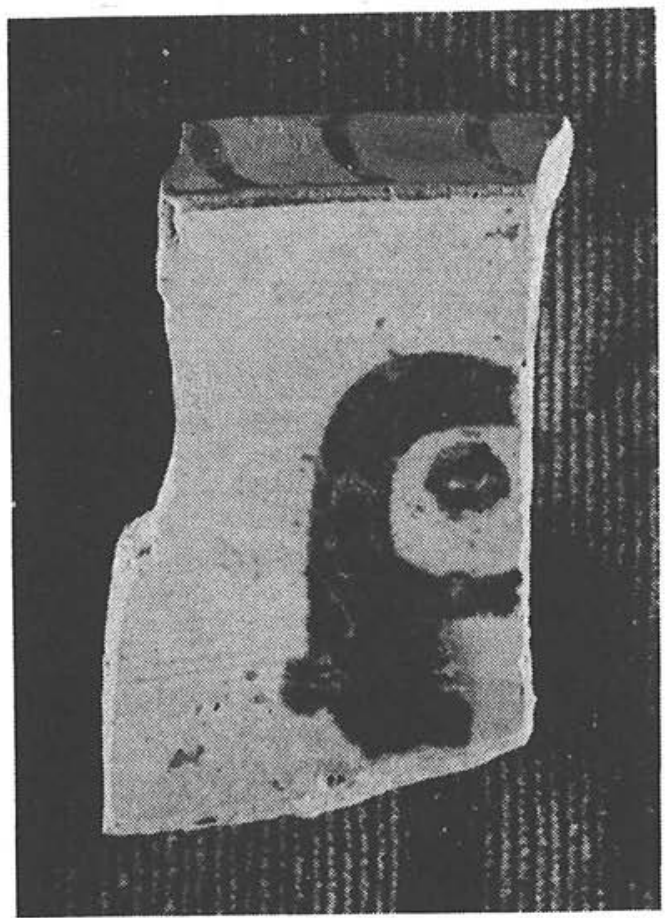

Figura 3.-Fotografia del fragmento menor. 


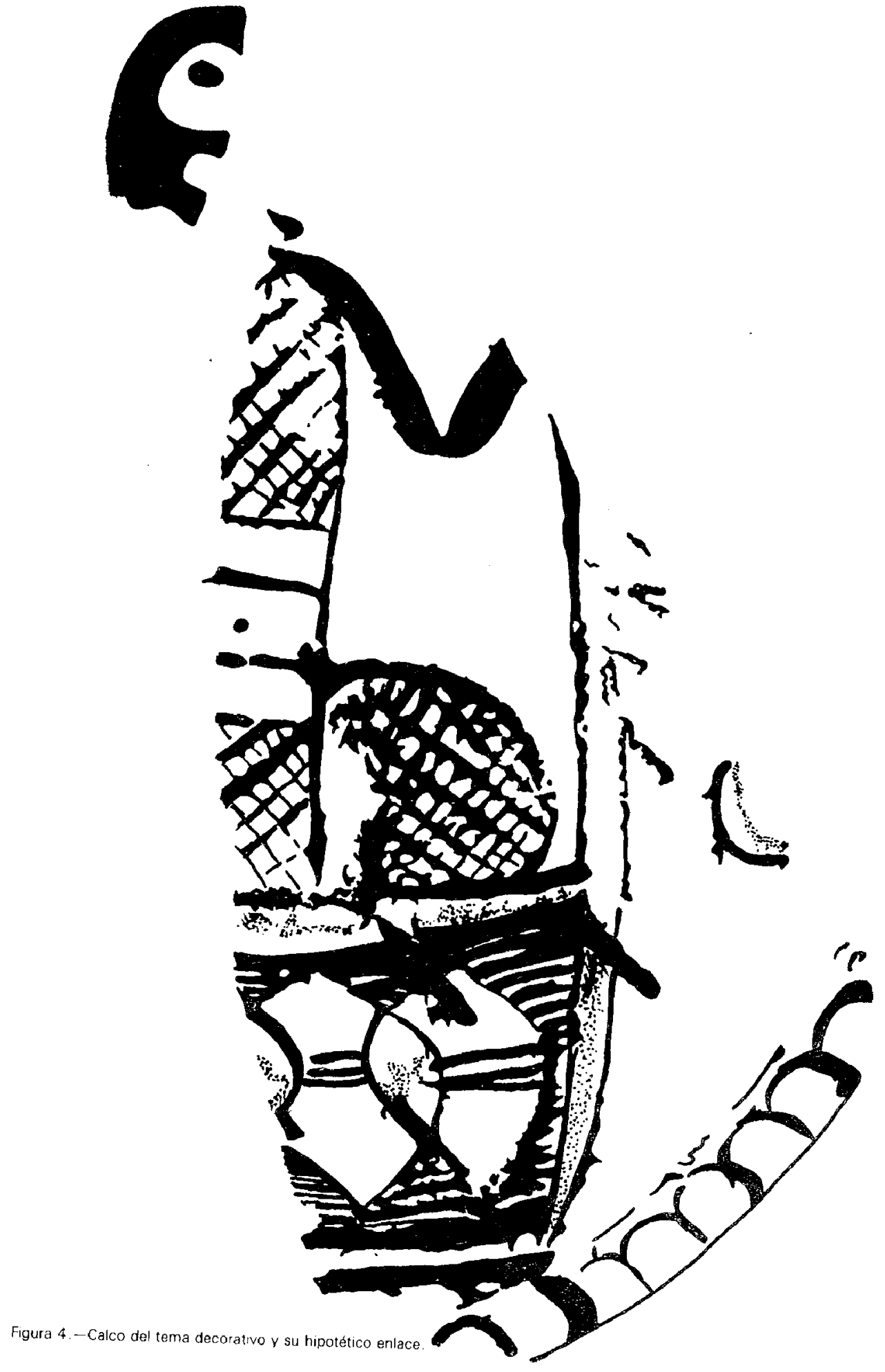




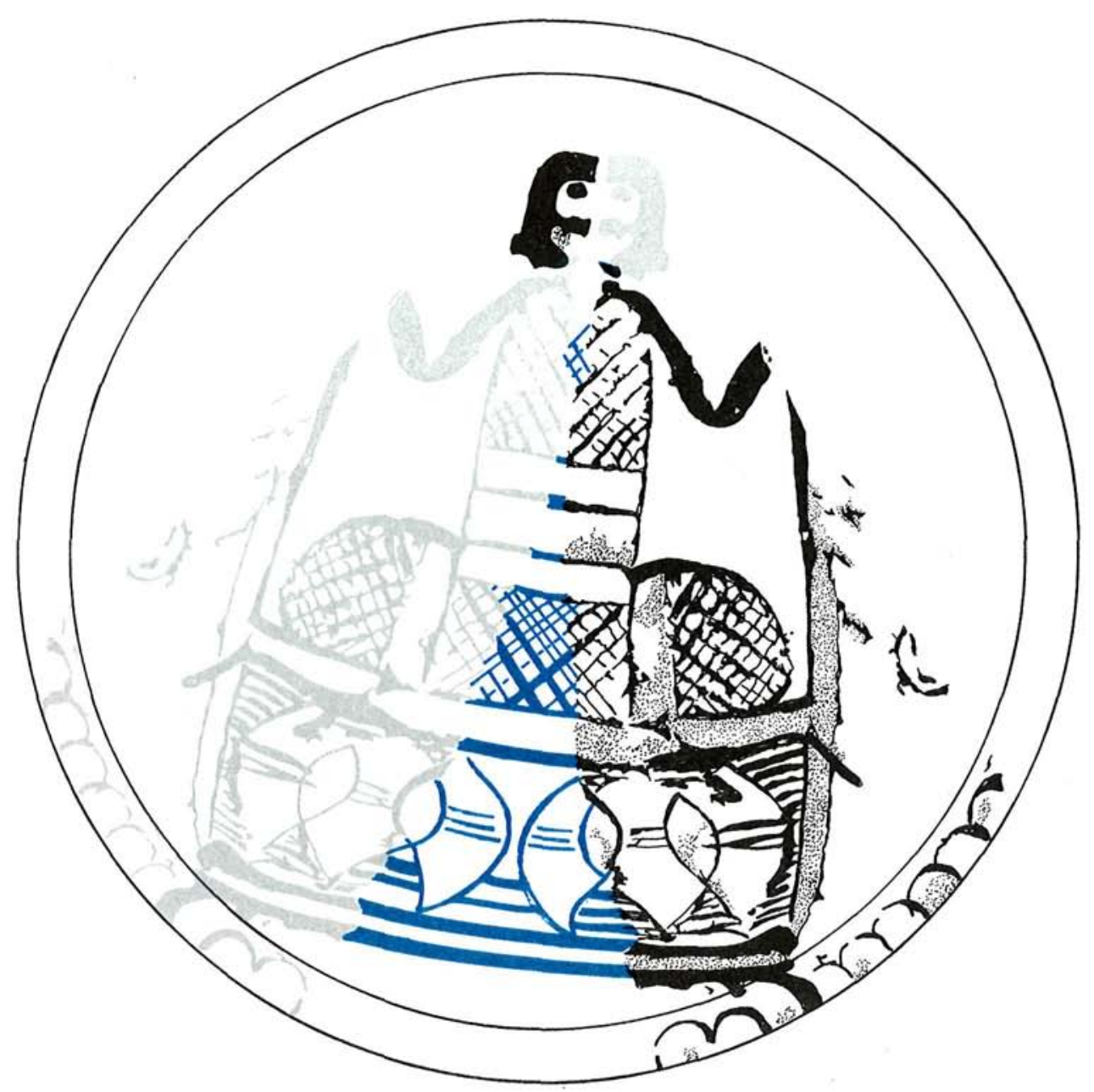

Figura 5.-Desarrollo simétrico del tema decorativo: En oscuro, el motivo conservado; en claro, la proyección simétrica, y en gris, la decoración restituida. 


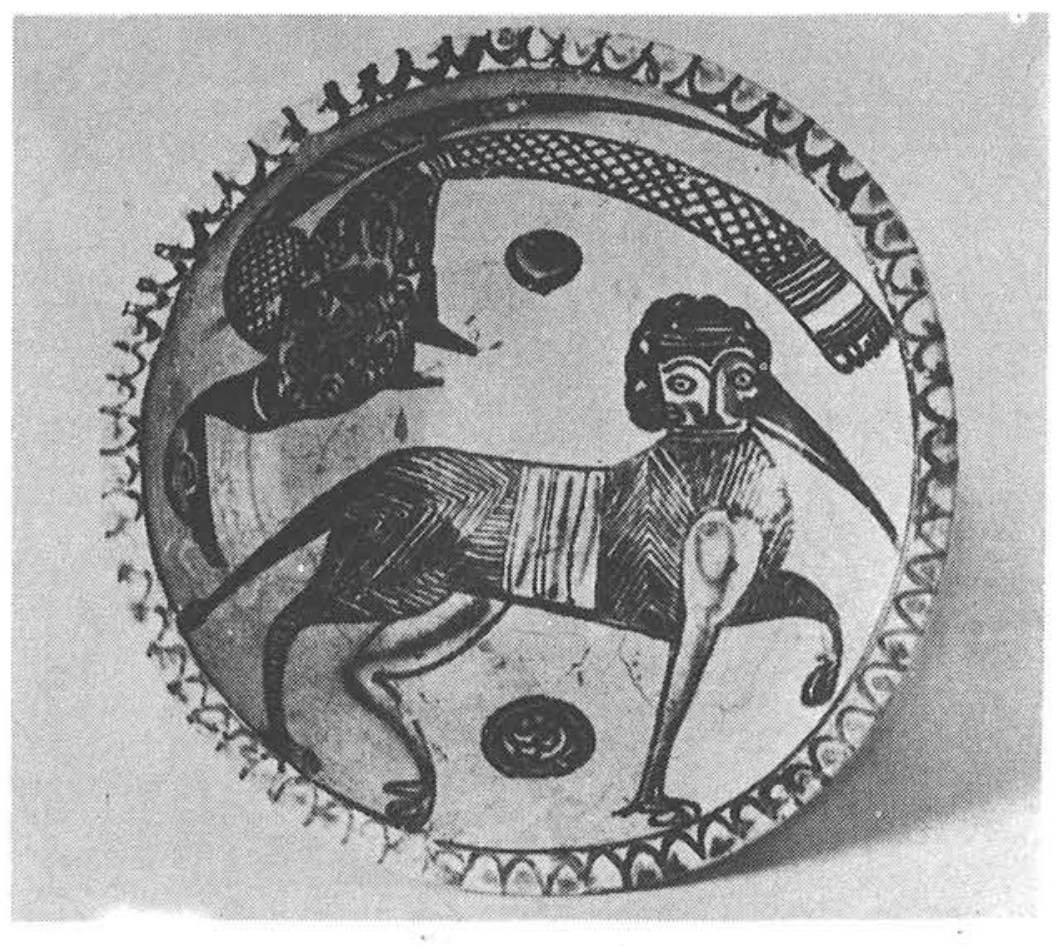

Figura 6. - Bacino 2 de la serie pisana (según Berti y Tongiorgi). 

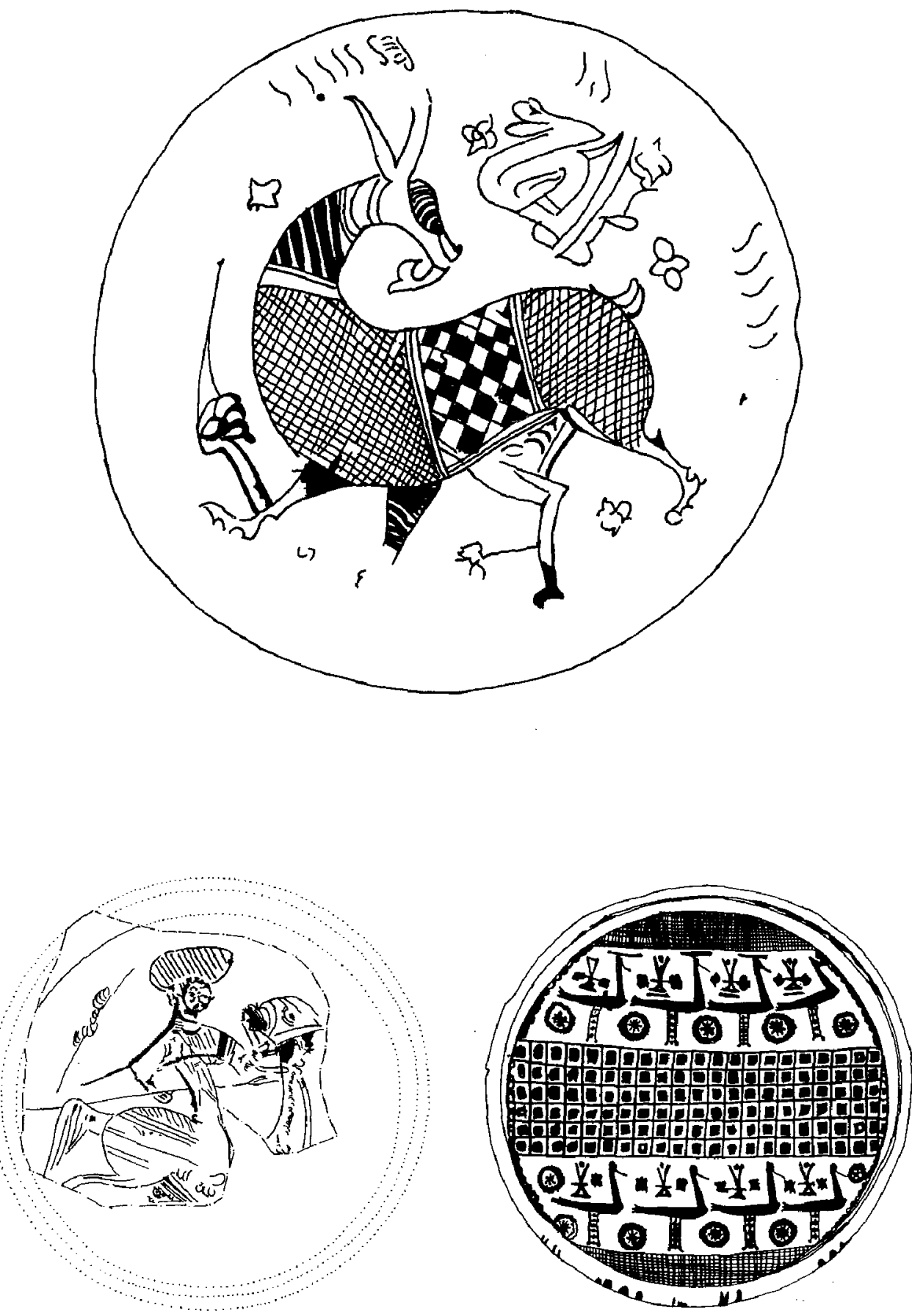

Figura 7.-Los ataifores publicados por Daoulatli: a) procedente de Qayrawān; b) Sabra; c) Raqqāda. 


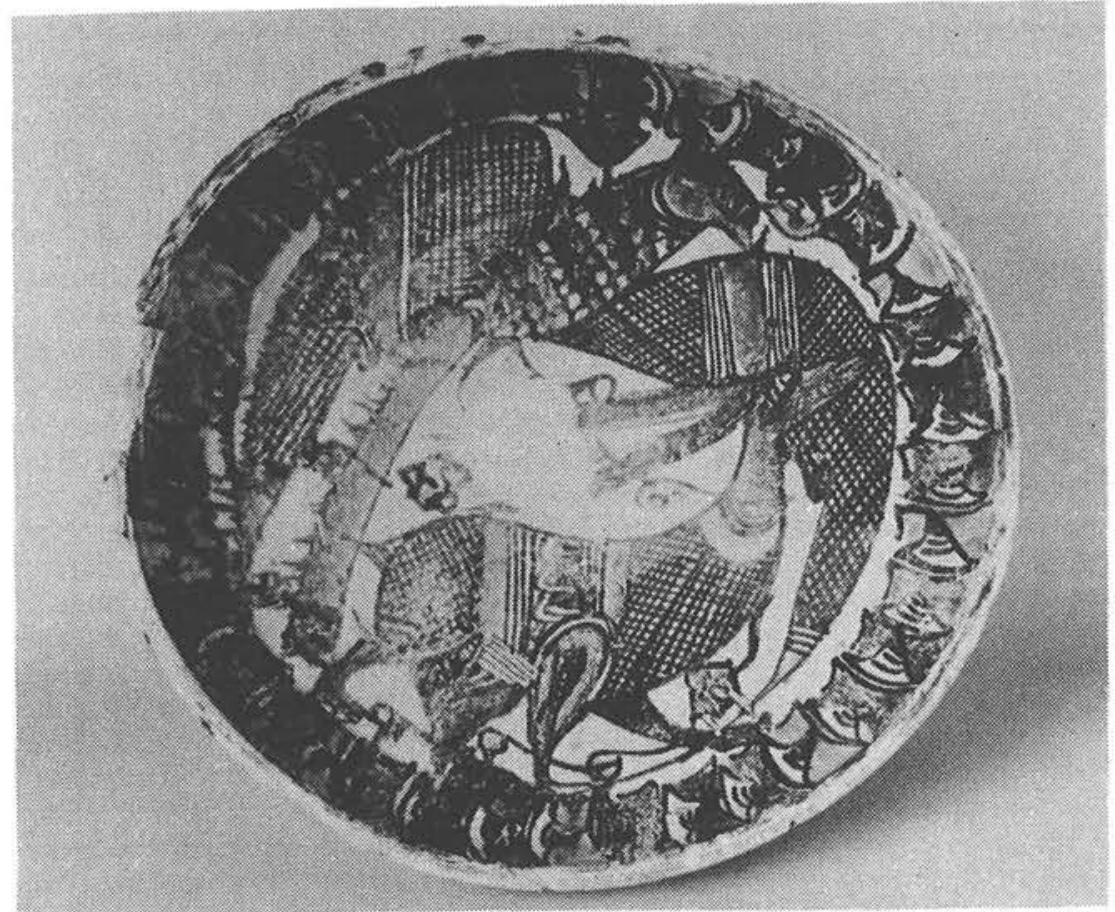

Figura 8.-El ataifor 58 de la serie pisana (según Berti y Tongiorgi). 


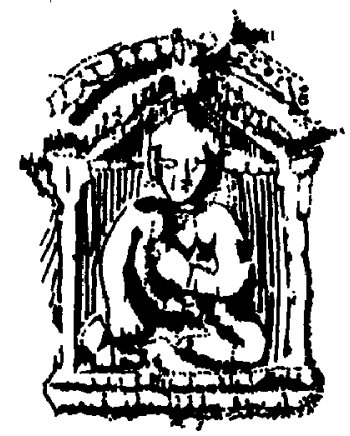

Figura 9 -Figura en majestad sobre marfil del Museo Victoria y Albert.

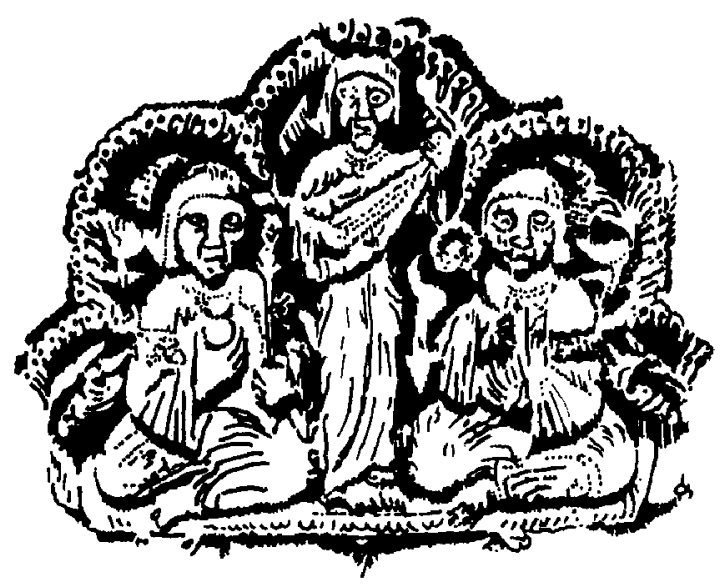

Figura 10. - Figuras laterales sobre marfil del Museo del Louvre. 


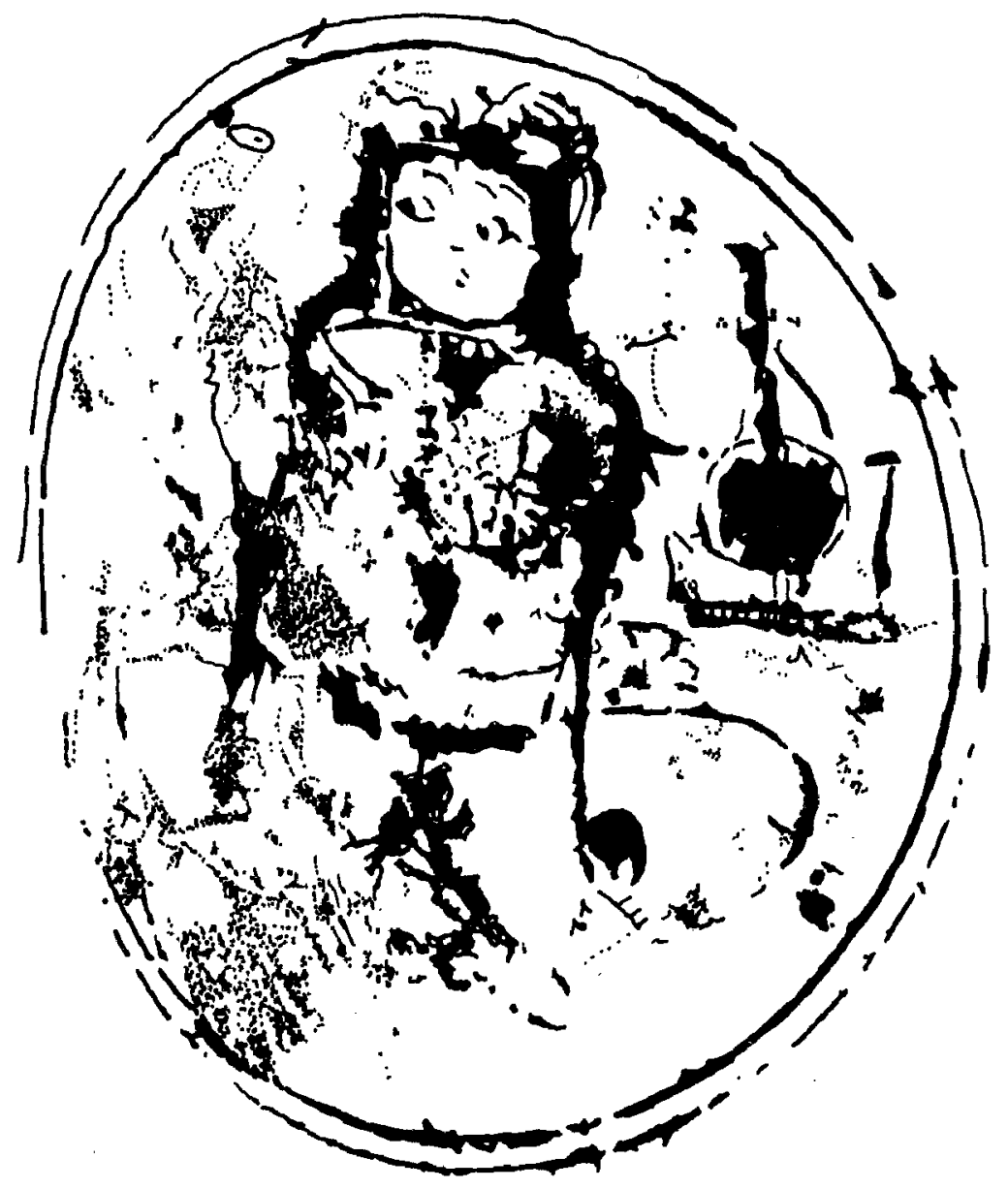

Figura 11 . - Figura en majestad, pintada sobre marfil, de la Walters Arts Gallery. 

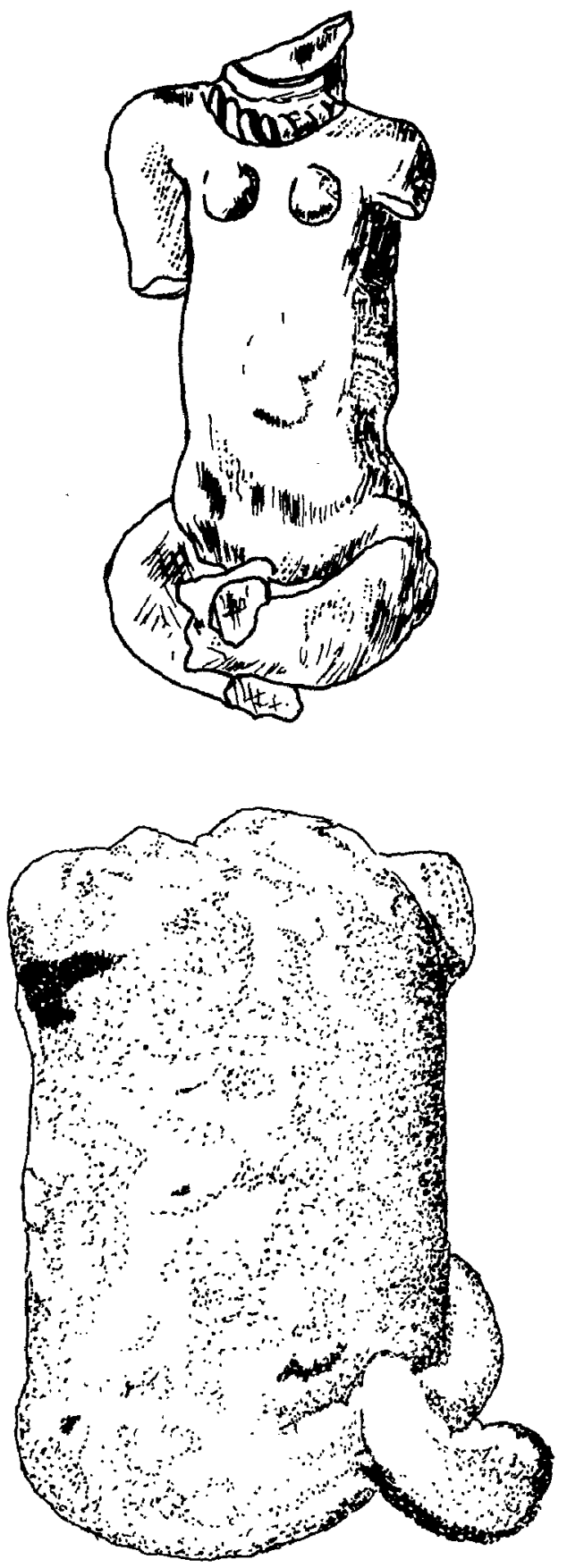

Figura 12.-a) Orante de Susa (según Rosen Ayalon); b) el orante de Sabra (según Zbiss) 